\title{
Supporting patients with low health literacy: what role do radiation therapists' play?
}

\author{
Dr Sian K Smith ${ }^{1, *}$, Ms Yunyun Zhu ${ }^{2}$, Dr Haryana M Dhillon ${ }^{3,4}$, \\ A/Prof Chris G Milross ${ }^{3,5}$, Dr Jennifer Taylor ${ }^{6}$, Dr Georgia Halkett ${ }^{7}$, Dr Elvira Zilliacus ${ }^{1}$ \\ 1 Psychosocial Research Group, Prince of Wales Clinical School, Faculty of Medicine, \\ University of New South Wales, Sydney, NSW, Australia.
}

2 Faculty of Medicine, UNSW, Sydney, NSW, Australia

3 Central Clinical School, Sydney Medical School, University of Sydney, NSW, Australia.

4 Psycho-Oncology Cooperative Research Group (PoCoG), School of Psychology, Faculty of Science, University of Sydney, Sydney, NSW, Australia.

5 Sydney Cancer Centre, Department of Radiation Oncology, Royal Prince Alfred Hospital, Sydney, NSW, Australia.

6 Sydney Medical School, University of Sydney, Sydney, NSW, Australia.

${ }^{7}$ Western Australia Centre for Cancer and Palliative Care/Curtin Health Innovation Research Institute, Curtin University Perth, Western Australia

* Corresponding author: Dr Sian K Smith

Address: Psychosocial Research Group, Prince of Wales Hospital, Dickinson Building Level 3, Barker Street, Randwick, NSW 2031, Australia.

Email: sian.smith@unsw.edu.au ; Telephone: +61 (0) 29382 2353; Fax: +61 (0) 293823372 


\begin{abstract}
Purpose: Health literacy plays a key role in a patient's ability to use health information and services, and can affect health outcomes. This study aimed to explore radiation therapists' perspectives on how they support people with lower health literacy who are undergoing radiotherapy.
\end{abstract}

Methods: Semi-structured interviews were conducted with 25 radiation therapists working in radiation oncology departments in New South Wales, Australia.

Results: The four key themes were: (1) the process of identifying a patient with low health literacy; (2) the perceived consequences of low health literacy; (3) managing and responding to the needs of different health literacy groups; and (4) recommendations to address low health literacy in radiotherapy. Radiation therapists appeared to make an informal, intuitive judgment about a patient's health literacy, using a variety of verbal and non-verbal cues as well as impromptu conversations with the multi-disciplinary team. Patients perceived to have lower health literacy were described as having greater difficulties assimilating knowledge and engaging in self-care. Although participants reported communicating to patient at a basic level initially, they subsequently tailored their communication to match a patient's health literacy. Strategies reported to communicate to low health literacy groups ranged from using lay language with minimal medical terminology, visual aids (photos), analogies, reiterating information, and asking family members with higher literacy to attend consultations.

Conclusion: A more structured approach to supporting patient with low health literacy and integrating health literacy training in radiation oncology departments may help to minimise the adverse outcomes typically experienced by this population.

Key words: Cancer $\cdot$ Radiation therapy $\cdot$ Health literacy $\cdot$ Communication $\cdot$ Health information $\cdot$ Qualitative research 


\section{Introduction}

Effective communication is essential to support patient understanding of health information and make informed decisions about medical care, particularly so in oncology where patients with cancer must assimilate unfamiliar information and make decisions during times of stress [1]. Efforts to optimize communication must account for an individual's health literacy, i.e. their capacity to apply their 'cognitive and social skills to gain access to, understand, and use information to promote and maintain good health'[2]. The three subtypes of health literacy (functional, communicative, critical) are defined in Table $1[2,3]$. The majority of health literacy research has operationalized health literacy as functional literacy, namely the ability to read and understand health information [4]. Increasingly research is assessing the impact of health literacy interventions on surrogate outcomes for diseases (e.g. diabetes self-management intervention measured impact on HgbA1c and other biomarkers) [5].

A substantial proportion of people living in developed countries have inadequate health literacy. In Australia, up to $60 \%$ of the general population (9 million) lack basic health literacy skills, particularly socially disadvantaged and minority populations [6]. There is evidence that lower health literacy is independently associated with higher mortality [7], lower knowledge of disease and prevention, and greater difficulties managing chronic conditions [8]. During consultations, patient with lower health literacy demonstrate problems understanding and recalling advice, ask fewer questions and appear less confident participating in decision-making [9]. Consequently, they often receive less information and report feeling dissatisfied with clinicians' communication [10].

There has been limited health literacy research in oncology, although studies suggest that patient are likely to struggle to understand concepts and medical terms commonly used in cancer, and those with lower health literacy may desire less involvement in decision-making [4, 11-14]. Little is known about how oncology health professionals identify patients with low health literacy in clinical practice, although this process is likely to be challenging. Patients with low literacy may be unaware of or conceal their comprehension problems [15]. Health literacy problems may be more obvious in populations who have limited skills conversing in the 
dominant language (e.g. ethnic minority groups), but less obvious in those speaking the dominant language, creating a 'hidden population' not easily identified by health professionals [16].

This study is one part of a program of health literacy research exploring how the radiation oncology team (e.g., radiation oncologists, radiation therapists, radiation oncology nurses) support patient with low health literacy (See Figure.1). Radiation therapists play a significant role as a daily point of contact and source of information for patient undergoing radiotherapy; they are involved in treatment planning, treatment delivery and the management of side-effects [17-22]. Although a number of studies [23, 24] have identified what information patients want during their treatment, they do not explore how radiation therapists support patient with different health literacy. We are reporting our findings from qualitative interviews with radiation therapist where we aimed to: (i) explore radiation therapists' perspectives on the role they play in supporting patient with low health literacy who are treated with radiotherapy for cancer, and (ii) investigate the strategies they report using to support patient with lower and higher health literacy skills. A greater understanding of the challenges faced by radiation therapists in practice may help to inform the development of interventions to optimize support for low health literacy populations. 


\section{Methods}

The study was approved by the Sydney Local Health Network, the two participating hospital sites, and the University of Sydney Human Research Ethics Committee.

\section{Theoretical approach}

Since this is a relatively new area of enquiry, a qualitative approach using semi-structured interviews was used. Hermeneutic phenomenology, in accordance with van Manen's philosophy guided the approach, enabling us to describe and interpret radiation therapists' lived experiences of supporting patient with low health literacy and how they made sense of their interactions [25].

\section{Participant recruitment}

Radiation therapists were recruited from metropolitan radiation oncology departments located in New South Wales, Australia. Participants were eligible to participate if they were qualified (completed radiation therapy training), and were regularly involved in treatment.

\section{Procedure}

Radiation therapists interested in taking part were given a participant information sheet, and informed consent was obtained. Interviews were conducted by SS, JT \& HD, either face-to-face or by telephone.

An interview schedule was used to: (i) collect socio-demographic information, and (ii) explore radiation therapists' perceptions of their role in supporting patient with low health literacy during the course of their radiotherapy. Examples of open-ended questions included: 'How do appointments with patient you consider to have higher health literacy differ from those with lower health literacy?', 'Are there any challenges with communicating to patient with different health literacy levels?', 'How do you check that patient have understood information?'. Interviews were audio-recorded and transcribed verbatim.

\section{Data Analysis}

Data analysis was informed by Miles and Huberman's (2002) conceptual qualitative framework [26]. Analysis started during data collection, allowing the interviewer to explore additional areas 
of interest. Two researchers (YZ and SS) familiarised themselves with the data by independently reading a sample of transcripts, and making notes on themes to inform the development of a preliminary coding framework. Themes were identified deductively in accordance with the aims, and inductively by maintaining close links with the data [27]. Transcripts were separately coded by YZ and SS using the preliminary coding framework, who then met to compare and contrast their coding interpretations and refine the framework. Discrepancies in coding were discussed and a final framework was developed. The whole data set was coded line-by-line into NVivo, Version 9. The results present each theme, with supporting exemplars. 


\section{Results}

Characteristics of the radiation therapists

Twenty-five radiation therapists participated, 18 females and 7 males, with a mean age of 31 years (range 22-54 years) (Table 2). Twenty participants were Anglo-Australian, and 19 spoke English as their primary language. Fourteen had 5 or less years experience, 4 between $6-10$ years, 3 between $11-20$ years and 4 more than 20 years.

\section{Themes}

The four key themes identified were: (1) the process of identifying patients with low health literacy; (2) the perceived consequences of low health literacy; (3) managing and responding to the needs of different health literacy groups; and (4) recommendations to address low health literacy in radiotherapy.

\section{The process of identifying patients with low health literacy}

\section{a. Definitions and indicators/signs of low health literacy}

Radiation therapists reported using a range of verbal and non-verbal cues to identify health literacy difficulties amongst patient receiving radiotherapy (Table 3). This appeared to be a subjective process repeated over the course of treatment, and shaped by their understanding of general and health literacy. Most participants defined health literacy as the application of reading skills and knowledge in a health context (functional health literacy). Others acknowledged radiotherapy as a specific medical context requiring different knowledge and skills. By contrast, others used educational attainment and English language skills as proxy estimates of health literacy problems.

People who have trouble understanding, say if you gave them a written pamphlet on side effects or explaining treatment (RT17). 
If they have low health literacy they don't have that basic understanding of the process that's happening to them and the concepts involved in both, diagnosis and treatment, the outcomes during treatment, the side effects and the management of those side effects (RT47).

It means they may have a lower education background, they may not understand some of our technical words, or even more complex English, or people from a foreign background (RT37).

In terms of verbal cues, participants referred to indicators such as: language ability; knowledge of cancer and radiotherapy; and how well they responded to questions. Some felt that patient with lower health literacy were more likely to have a limited vocabulary, difficulties articulating questions or ask the same question repeatedly, and display lower understanding of radiotherapy.

The language they [patients with low health literacy] use would be perhaps basic, probably use a lot of slang words and not forming well constructed sentences (RT 11).

The language they [patients with low health literacy] use would be perhaps basic, probably use a lot of slang words and not forming well constructed sentences (RT19).

The concepts of the radiation and the vocabulary we use they don't understand (RT50).

By contrast, non-verbal signs included: analyzing facial expressions and body language, observing their capacity to follow advice regarding the management of side-effects to considering socio-demographic characteristics.

I mean you're meeting them for about 15 minutes initially, so you can gather whether or not they're understanding by their facial expressions (RT13).

If they are from a part of Australia or a suburb that might be predominantly low literacy ... like a housing commission area, or if they're from out of Sydney, if they're from the country (RT32). 


\section{b. Challenges of identifying people with low health literacy}

Some radiation therapists found it hard to identify health literacy problems when patients concealed their difficulties (e.g., not seeking clarification, diverting the conversation, or appearing to comprehend information).

Patients getting embarrassed or, don't want to make it seem like they're not understanding what seems to be a simple process (RT14).

Others reported that it was difficult to determine a patient's capacity to understand due to other factors interfering with information processing, such as their emotional state (shock, anxiety, stress), cognitive impairment, and drug and /or alcohol dependence. Consequently, participants felt that it important to assess understanding at each appointment as it was likely to fluctuate throughout treatment.

It is difficult to know if they have difficulty understanding because of the enormity of the situation because of what they are dealing with or whether it is a literacy thing. (RT12).

Participants' accounts suggested they found it easier to identify health literacy problems among patient from ethnic minority groups with limited English and poorer communication skills. By contrast, participants seemed less aware of potential health literacy limitations among patient who spoke English.

It's patients that aren't understanding what would be assumed to be normal conversation or colloquial conversation perhaps from a non-English speaking background (RT20).

\section{c. Flagging health literacy issues}

Participants described the different ways their team discussed health literacy issues. Some reported that the radiation oncologist would identify any health literacy problems at the initial 
consultation $^{* \dagger}$ (See Figure. 2 for patient flow through radiotherapy preparation and treatment), and either record their observations in the patient's notes or mention it to the radiation therapist.

If the oncologist thinks that a patient might have difficulty understanding they would give us a heads up, give us a call, or even put it in the patient's notes (RT37).

Radiation therapists reported alerting members of the team, either in writing, in passing, or at department meetings if they perceived that a patient was struggling to understand. However, this was not routinely done and issues were more likely to be raised when patients had limited English. Some reported that it was difficult to know how to raise issues or notify others because there was no established protocol.

I would try and write down for colleagues in future, “This person has low literacy, can't read or write, so just make sure you verbalise everything for them." (RT38).

I wouldn't know what avenue to flag it to...I don't think flagging it to the doctor would go down too well (RT12).

\section{Perceived impact/consequences of low health literacy}

a. Knowledge of radiation therapy - acquiring and comprehending information Patient with lower health literacy were described as having limited knowledge of modern radiotherapy, holding incorrect ideas about their disease, treatment and potential side effects - a

\footnotetext{
* Halkett et al. (2010) identified 4 key time points in the radiotherapy treatment pathway: Time 1: Meeting the radiation oncologist, Time 2: The planning appointment, Time 3: First day of treatment and Time 4: Approaching the end of treatment.

18. Halkett, G.K.B., et al., Meeting breast cancer patients' information needs during radiotherapy: what can we do to improve the information and support that is currently provided? European Journal of Cancer Care, 2010. 19(4): p. 538-47.
} 
common misconception was that treatment would make them 'radioactive'. This was partly due to relying on outdated experiences of family, friends and media. Participants also reported that they had difficulties understanding the difference between chemotherapy and radiotherapy, and palliative and curative treatment.

They're relying on I suppose folklore, you know people say my grandfather had treatment back in the 1950s and he was very sick. So they may not have up to date information because of the lack of resources available to them (RT33).

Quite often a patient will come in with a palliative treatment...So the doctor might say, "Yeah, it will help this and it will make you get better" and the patient has interpreted, "Make you better" as "I will be cured" (RT32).

By contrast, participants believed that patient with higher health literacy were more likely to have conducted their own research, and seemed better informed and able to critically assess relevant information pertaining to their situation.

You definitely see better care [among patient with higher health literacy] because they probably do more research and are a bit more proactive in trying to find, and are better able to sort of find the resources that you might need to have that kind of care (RT17).

b. Self-care-managing the adverse side effects of treatment

Patients with lower health literacy were thought to experience greater difficulties following instructions on management of treatment-related side-effects, particularly skincare. Such problems were thought to arise from patients not knowing how to report their side effects or fully comprehend that health behaviours (e.g. smoking) exacerbate side effects. Participants did acknowledge that they may have overestimated a patient's ability to manage side effects, and did not adequately prepare patients. They were also concerned that patients may not receive enough support to manage their ongoing side effects after they had completed treatment and were potentially at risk of hospital readmission. 
A lot of the head and neck cancers that we treat receive a complex plan... a number of them still smoke and drink and they might not understand those sort of concepts of seeking help when the side effects are minor or bad (RT47).

There would be some things that are important during and after treatment and because we don't see patients after treatment at all, so if their understanding of what they were supposed to do after treatment was not understood that could result in them having to return to hospital for additional care (RT20).

\section{Managing and responding to the needs of different health literacy groups}

\section{a. Timing and quantity of information}

Irrespective of health literacy, participants acknowledged the importance of staggering information, and were mindful not to overwhelm patients with information all at one time (Table 4). As treatment progressed, they built on and reiterated information, giving patients the opportunity to ask questions. Participants distinguished between the treatment planning appointment and the first day of treatment as critical points where they provided patients with a basic framework of information focused on the practical aspects of treatment - how treatment is planned and what daily treatment entails. By contrast, side effect information was not provided until treatment had commenced.

The first day of treatment we'll give them a brief introduction about what I'm going to do... I limit the information to the important things. Even for well educated people I think that's too much. I tell them the side effects to expect after a few weeks of treatment, because they change as the treatment goes on (RT33).

\section{b. Tailoring communication to match health literacy level}

The treatment planning appointment offered the first opportunity to gauge a patient's health literacy; communication pitched starts at a basic level and is tailored to match a patient's ability. 
To enhance communication among lower health literacy groups, participants reported using plain language and analogies (e.g. comparing skin reactions to sunburn):

I might say 'you might feel a bit sick in the stomach' instead of saying nausea. For diarrhoea, I might say 'go to the bathroom a bit more for your bowel movements' (RT33).

For parts of the body we wouldn't say the names of bones, we'd probably just say your arm or your hip or your leg. We don't use the word X-ray we say picture (RT19).

Although more detailed information was provided to higher health literacy groups, participants acknowledged that even those with adequate general literacy may be unfamiliar with technical terms (e.g., bolus, irradiation).

I find those patients tend to ask about how it actually works, the whole system behind the actual machines, and that's when I can go into depth about it (RT49).

You might throw in a few more technical terms. But if they are not from a radiation therapy background they probably wouldn't understand (RT12).

Most participants reported using a combination of written, pictorial and verbal communication, preferring verbal communication as it enabled them to tailor their language. To reinforce verbal explanations of the treatment procedure, visual aids were used (photos of the treatment machine, mask models). Participants also provided patients with information resources produced by the department (e.g., DVDs and written materials), although only a few participants reported checking whether patient's had fully understood it.

I make sure I call my patients a day or two before their planning appointment, and I ask them, did you read the books, do you have any questions, I say then that I will explain that to them when they come because you don't want to overload them (RT13). 
Irrespective of health literacy, participants avoided using statistics to convey risk information, and used qualitative descriptors such as 'not likely to happen'. Participants appeared more confident in their ability to communicate information about the chances of experiencing side effects, and less comfortable with providing information about the efficacy of treatment (e.g., survival, the risk of subsequent cancers), and would refer them to the oncologist.

Every time there is a question, 'what is the chance that this works?'. Those questions are always referred to the radiation oncologist (RT14).

\section{c. Enhancing understanding}

Radiation therapists reported a range of strategies to optimize recall and comprehension throughout treatment. These included; reiterating information; encouraging patients to seek clarification and ask questions; asking patients to paraphrase information they had received in their own words (teach-back strategy); limiting the amount of information provided at each encounter; confirming comprehension; and appointment reminders. Some also promoted the presence of a support person with higher literacy, to help reinforce information.

I tend to check that they've understood what they've previously been told, so when discussing side effects, 'has the doctor spoken to you about side effects?' and 'what did they tell you?' and actually get them to tell me before I tell them (RT42).

I do find if they don't seem to be retaining the information, I will grab a family member (RT17). 


\section{Recommendations to address low health literacy in radiotherapy}

Many participants highlighted the lack of guidance on supporting patients with low health literacy. Potential solutions included developing protocols on notification of the team to health literacy issues and integrating health literacy in communication skills training programs.

So even training for us dealing with people in this certain area because it does take a different skill, you have to listen, and you have to be able to pick up cues better than the average person, and perhaps have the patience to re-explain (RT38).

Participants also suggested improving the quality of information resources (e.g., written brochures, DVDs) for patients with health literacy difficulties. Strategies to achieve this included: greater use of visuals (diagrams, photos), using plain language (e.g. minimizing or defining medical terminology), and incorporating patient narratives to make the information more meaningful. Several participants also felt that providing a private area for them to consult with patients may help to identify health literacy difficulties in a sensitive way. 


\section{Discussion}

This study provides insight into the issues faced by radiation therapists when supporting patient with low health literacy. The results indicate that radiation therapists make informal, intuitive judgments about health literacy as a patient progress through treatment, using a variety of verbal and non-verbal cues as well as impromptu conversations with the team. In turn, lower health literacy was thought to negatively impact on the ability to assimilate knowledge about radiotherapy, and skills important for self-care. Although radiation therapists reported initially communicating with all patients at a basic level, they subsequently tailored their communication to match a patient's health literacy using a range of strategies (as in table 4).

Participants appeared to have a good understanding of health literacy. Although, most defined it as functional skills to acquire knowledge, they implicitly spoke of other types of health literacy interactive and critical. They recognized that different health contexts require different skills, thus, even individuals with good general literacy skills may experience difficulties on entry to a clinical domain [28]. Our data supports the idea that identifying health literacy problems appears to be more challenging in certain populations than others [16]; with radiation therapists more likely to report problems arising during interactions with patient from ethnic minorities with limited English. This implies that health literacy difficulties among patient able to speak English (the 'hidden population') may go unrecognised in health settings [16, 29, 30]. Health professionals need to be mindful that proxy estimates of health literacy (e.g. education, ethnicity) may lead to stereotyping, and over- or underestimation a patient's skills [31, 32].

In line with existing research, participants perceived that lower health literacy compromised a patient's ability to comprehend information [8], often leading to poorer knowledge and more misconceptions [33]. We note that radiotherapy is poorly understood in the general population (Long 2001). Patient with lower health literacy were also perceived to experience greater difficulties following self-care advice. This supports evidence in other clinical contexts indicating that lower health literacy is associated with poorer adherence to medication and poorer self-care management, increased hospitalizations and use of emergency services [8, 34]. Evidence from other areas also suggests that health literacy interventions can improve 
comprehension, self-management behaviour and consequently dependent health-related outcomes [5].

Participants acknowledged that individuals are more receptive to information at different stages of treatment, and staggered information. Previous studies have shown that staggering information is an effective way to reduce patient anxiety [24]. Consistent with existing work, the treatment planning appointment and first day of treatment were key points to convey information about treatment procedures and discovering what daily treatment will involve [23]; and radiation therapists appear less confident in communicating to patient about the pros and cons of treatment, and more confident in providing information about side effects [20].

Radiation therapists seemed to use an approach described as 'health literacy universal precautions' whereby it is assumed everyone will have difficulties understanding and communication pitched at a basic level to all patients [35]. Participants did; however, report providing more technical information to those perceived to have higher health literacy, and used shorter lay explanations for those with lower health literacy. Similarly, previous research has shown that doctors provide less information to patient from lower socio-economic and ethnic minority groups [36-38]. Further discussion is warranted. Should patient from disadvantaged groups receive less detailed information? Possibly, if they understand the core facts, enabling them to engage better in self-care. Understanding the gist or bottom-line meaning of information may be more meaningful to patients long-term as it is less susceptible to factors such as anxiety which can impair comprehension [39]. Furthermore, lower health literacy is associated with a lower need for information about treatment [12].

Consistent with existing recommendations [40-44], participants enhanced communication by using plain language, limited medical language, using visuals, encouraging questions, and reiterating information. 'Teach-back' (confirming understanding by asking patients to describe information in their own words), and analogies to convey complex and abstract concepts, were also used [45]. Consultations which contained more analogies and metaphors elicit higher patient 
ratings about the clarity of information [46]. Further work could investigate whether analogies enhance understanding across different health literacy groups.

The suggestions proposed by participants about systemic improvements for patient with low health literacy are similar to those suggested by others [43] (e.g., improving suitability of patient education materials and creating a sensitive environment to support patient disclosure). Currently health literacy is discussed in an ad-hoc way within radiation oncology departments, protocols to flag health literacy issues are a first step toward systemic change to address this challenge. Integrating health literacy training into existing communication skills training will raise awareness of issue and provide guidance on supporting low health literacy groups. To our knowledge, no such training exists in Australia.

Some limitations of the study should be noted. These self-report findings do not shed light on how the radiation therapists actually interact with patients and the strategies they use to assess comprehension. To address this gap, we are audio-recording consultations between radiation oncology health professionals and patients to examine the linguistic processes underpinning their interactions. It is possible that our sample represents radiation therapists who may be more aware of health literacy. Radiation therapists from different states and settings (e.g. rural) may have different experiences; further research is needed with radiation therapists in different geographical locations. These results may be specific to the Australian radiotherapy setting, but they may be of interest to other oncology departments around the world.

Conclusion: To date, little health literacy work has been carried out in oncology. Although radiation therapists were aware of the potential impact of low health literacy, a structured approach to identifying patients with low health literacy in radiation oncology departments may reduce undesirable treatment side-effects they typically experience. Health literacy training for health professionals is required to increase awareness of low health literacy, along with practical strategies to overcome this as a communication barrier and its likely impact of healthcare outcomes. 


\section{Acknowledgements}

The authors wish to thank the radiation therapists who participated in this study. This first author is supported by an Australian National Health and Medical Research Council Early Career

Fellowship (no. 1034912). The project was supported by a University of Sydney Medical School, Early Career Researcher Grant secured by Dr Smith.

\section{Conflict of interest statement}

The authors do not have any conflicts of interest to declare.

\section{References}

1. Jefford, M. and M.H.N. Tattersall, Informing and involving cancer patients in their own care. The Lancet Oncology, 2002. 3(10): p. 629-637.

2. Nutbeam, D., Health literacy as a public health goal: a challenge for contemporary health education and communication strategies into the 21st century. Health Promotion International, 2000. 15(3): p. 259-267.

3. Nutbeam, D., The evolving concept of health literacy. Social Science \& Medicine, 2008. 67(12): p. 2072-2078.

4. Koay, K., P. Schofield, and M. Jefford, Importance of health literacy in oncology. AsiaPacific Journal of Clinical Oncology, 2012. 8(1): p. 14-23.

5. Sheridan, S.L., et al., Interventions for Individuals with Low Health Literacy: A Systematic Review. Journal of Health Communication, 2011. 16(sup3): p. 30-54.

6. ABS, Adult Literacy and Life Skills Survey, Summary Results2006, Canberra: Australian Bureau of Statistics: Australian Government Publishing Service. Cat No. 4228.0.

7. Bostock, S. and A. Steptoe, Association between low functional health literacy and mortality in older adults: longitudinal cohort study. BMJ, 2012. 344.

8. $\quad$ Berkman, N.D., et al., Low Health Literacy and Health Outcomes: An Updated Systematic Review. Annals of Internal Medicine, 2011. 155(2): p. 97-107.

9. Ishikawa, H., et al., Patient health literacy and patient-physician information exchange during a visit. Family Practice, 2009. 26(6): p. 517-523.

10. Schillinger, D., et al., Functional health literacy and the quality of physician-patient communication among diabetes patients. Patient Education and Counseling, 2004. 52(3): p. 315-323.

11. Pieterse, A.H., et al., Lay understanding of common medical terminology in oncology. Psycho-Oncology, 2012. doi: 10.1002/pon.3096.

12. Zeguers, M., et al., The Information Needs of New Radiotherapy Patients: How to Measure? Do They Want to Know Everything? And if Not, Why? International journal of radiation oncology, biology, physics, 2012. 82(1): p. 418-424.

13. Douma, K., et al., Do patients' information needs decrease over the course of radiotherapy? Supportive Care in Cancer, 2012. 20(9): p. 2167-2176. 
14. Kilbridge, K.L., et al., Lack of Comprehension of Common Prostate Cancer Terms in an Underserved Population. J Clin Oncol, 2009. 27(12): p. 2015-2021.

15. Wolf, M.S., et al., Patients' Shame and Attitudes Toward Discussing the Results of Literacy Screening. Journal of Health Communication: International Perspectives, 2007. 12(8): p. 721 - 732.

16. Easton P, Entwistle V.A, and Williams B, Health in the 'hidden population' of people with low literacy. A systematic review of the literature. BMC Public Health, 2010. 10: : p. doi: 10.1186/1471-2458-10-459.

17. Halkett, G.K.B. and L.J. Kristjanson, Patients' perspectives on the role of radiation therapists. Patient Education \& Counseling, 2007. 69(1-3): p. 76-83.

18. Halkett, G.K.B., et al., Meeting breast cancer patients' information needs during radiotherapy: what can we do to improve the information and support that is currently provided? European Journal of Cancer Care, 2010. 19(4): p. 538-47.

19. Bolderston, A., Mixed messages? A comparison between the perceptions of radiation therapy patients and radiation therapists regarding patients' educational needs. Radiotherapy, 2008. 14: p. 111-119.

20. Halkett, G.K.B., et al., Effective communication and information provision in radiotherapy - the role of radiation therapists. Journal of Radiotherapy in Practice, 2010. 9(01): p. 3-16.

21. Alfieri, F., et al., Radiation therapist-led weekly patient treatment reviews. The Radiographer, 2009. 56: p. 44-48.

22. Martin, K. and D. Hodgson, The role of counselling and communication skills: how can they enhance a patient's 'first day' experience? Journal of Radiotherapy in Practice, 2006. 5: p. 157-164.

23. Halkett, G.K., et al., Meeting breast cancer patients' information needs during radiotherapy: What can we do to improve the information and support that is currently provided? European Journal of Cancer Care, 2010. 19(4): p. 538-547.

24. D'haese $\mathrm{S}$, et al., The effect of timing of the provision of information on anxiety and satisfaction of cancer patients receiving radiotherapy. J Cancer Educ 2000;15:223-7., 2000. 15(223-7).

25. van Manen M, Researching the lived experience: human science for an action sensitive pedagogy. Second edition1997, Ontario: Althouse Press.

26. Huberman AM and Miles MB, The qualitative researcher's companion2002: Sage Publications, Inc.

27. Pope, C., S. Ziebland, and N. Mays, Qualitative research in health care: Analysing qualitative data. BMJ, 2000. 320(7227): p. 114-116.

28. Nutbeam, D., Defining and measuring health literacy: what can we learn from literacy studies? International Journal of Public Health, 2009. 54(5): p. 303-305.

29. Marcus, E.N., The Silent Epidemic - The Health Effects of Illiteracy. New England Journal of Medicine, 2006. 355(4): p. 339-341.

30. Bass, P.F.I., et al., Residents' Ability to Identify Patients with Poor Literacy Skills. Academic Medicine, 2002. 77(10): p. 1039-1041.

31. Kelly, P.A. and P. Haidet, Physician overestimation of patient literacy: A potential source of health care disparities. Patient Education and Counseling, 2007. 66(1): p. 119122. 
32. Lindau, S.T., A. Basu, and S.A. Leitsch, Health Literacy as a Predictor of Follow-Up After an Abnormal Pap Smear: A Prospective Study. Journal of General Internal Medicine, 2006. 21(8): p. 829-834.

33. Long LE, Being Informed: Undergoing Radiation Therapy. Cancer Nursing, 2001. 24(6): p. 463-468.

34. Dewalt, D.A., et al., Literacy and health outcomes: a systematic review of the literature. Journal of General Internal Medicine, 2004. 19(12): p. 1228-39.

35. DeWalt, D.A., et al., Developing and testing the health literacy universal precautions toolkit. Nursing Outlook, 2011. 59(2): p. 85-94.

36. Willems, S., et al., Socio-economic status of the patient and doctor-patient communication: does it make a difference? Patient Education and Counseling, 2005. 56(2): p. 139-146.

37. Waitzkin, H., Information giving in medical care. Journal of Health and Social Behavior, 1985. 26: p. 81-101.

38. Johnson RL, et al., Patient race/ ethnicity and quality of patient-physician communication during medical visits. Am J Public Health, 2004. 94(12): p. 2084-2090.

39. Reyna, V.F., A theory of medical decision making and health: Fuzzy Trace Theory. Medical Decis Making, 2008. 28: p. 850-865.

40. Davis, T.C., et al., Health literacy and cancer communication. A Cancer Journal for Clinicians, 2002. 52: p. 134-149.

41. Manning, D.L. and C. Dickens, Health literacy: more choice, but do cancer patients have the skills to decide? European Journal of Cancer Care, 2006. 15(5): p. 448-452.

42. Doak, C.C., et al., Improving comprehension for cancer patients with low literacy skills: Strategies for clinicians. CA Cancer J Clin, 1998. 48(3): p. 151-162.

43. Garcia SF, Hahn EA, and E. Jacobs, Addressing low literacy and health literacy in clinical oncology practice. The Journal of Supportive Oncology, 2010. 8: p. 64-69.

44. Houts, P.S., et al., The role of pictures in improving health communication: A review of research on attention, comprehension, recall, and adherence. Patient Education and Counseling, 2006. 61(2): p. 173-190.

45. Davis, T.C., et al., Health literacy and cancer communication. CA: a Cancer Journal for Clinicians, 2002. 52(3): p. 134-49.

46. Casarett D, et al., Can Metaphors and Analogies Improve Communication with Seriously Ill Patients? J Palliat Med, 2010. 13(3): p. 255-260. 
Figure 1. The Radiotherapy health literacy study - a comprehensive exploration of health literacy in the radiation oncology setting.

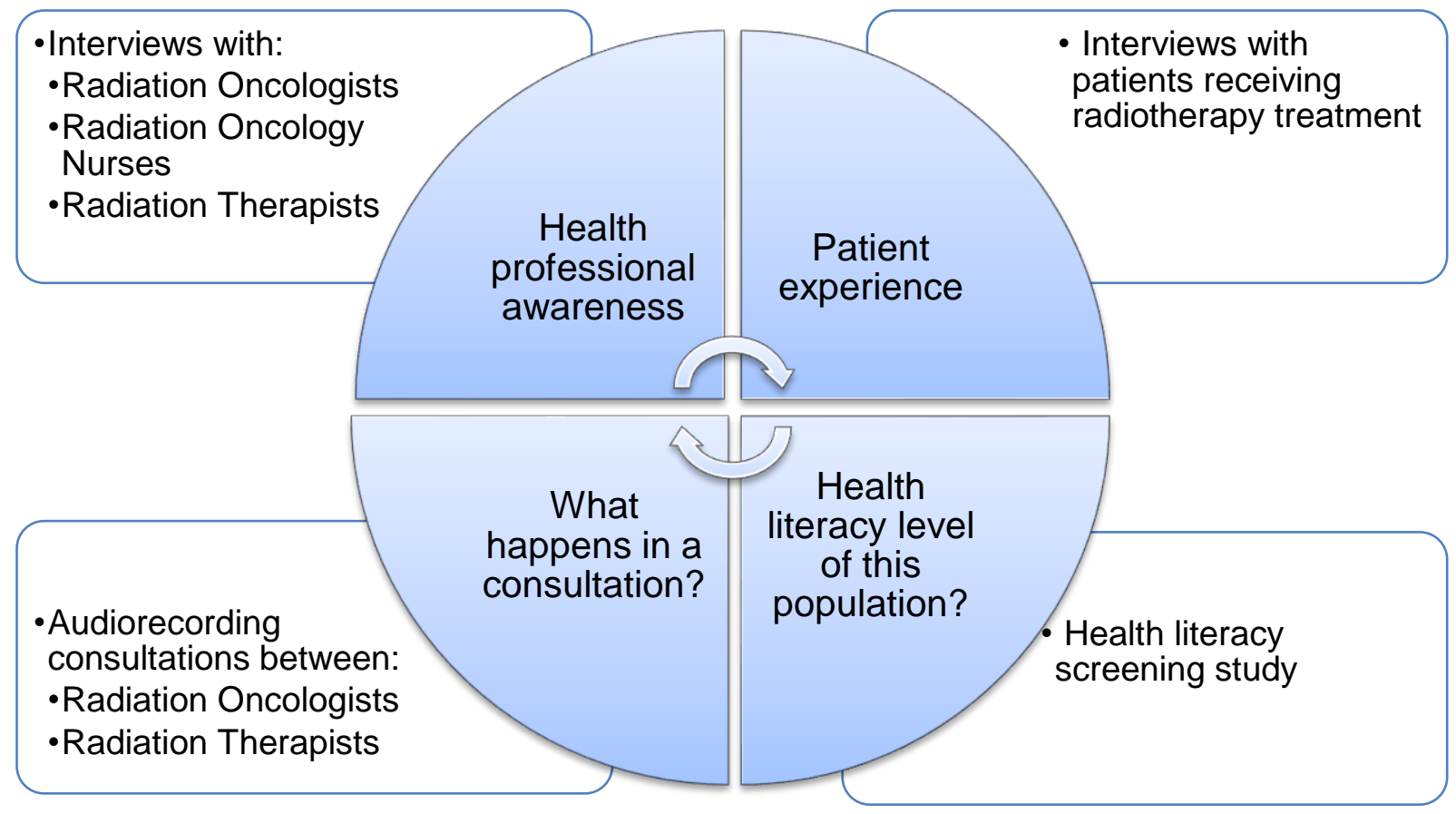


Figure 2. Patient flow through radiotherapy preparation and treatment ${ }^{*}$

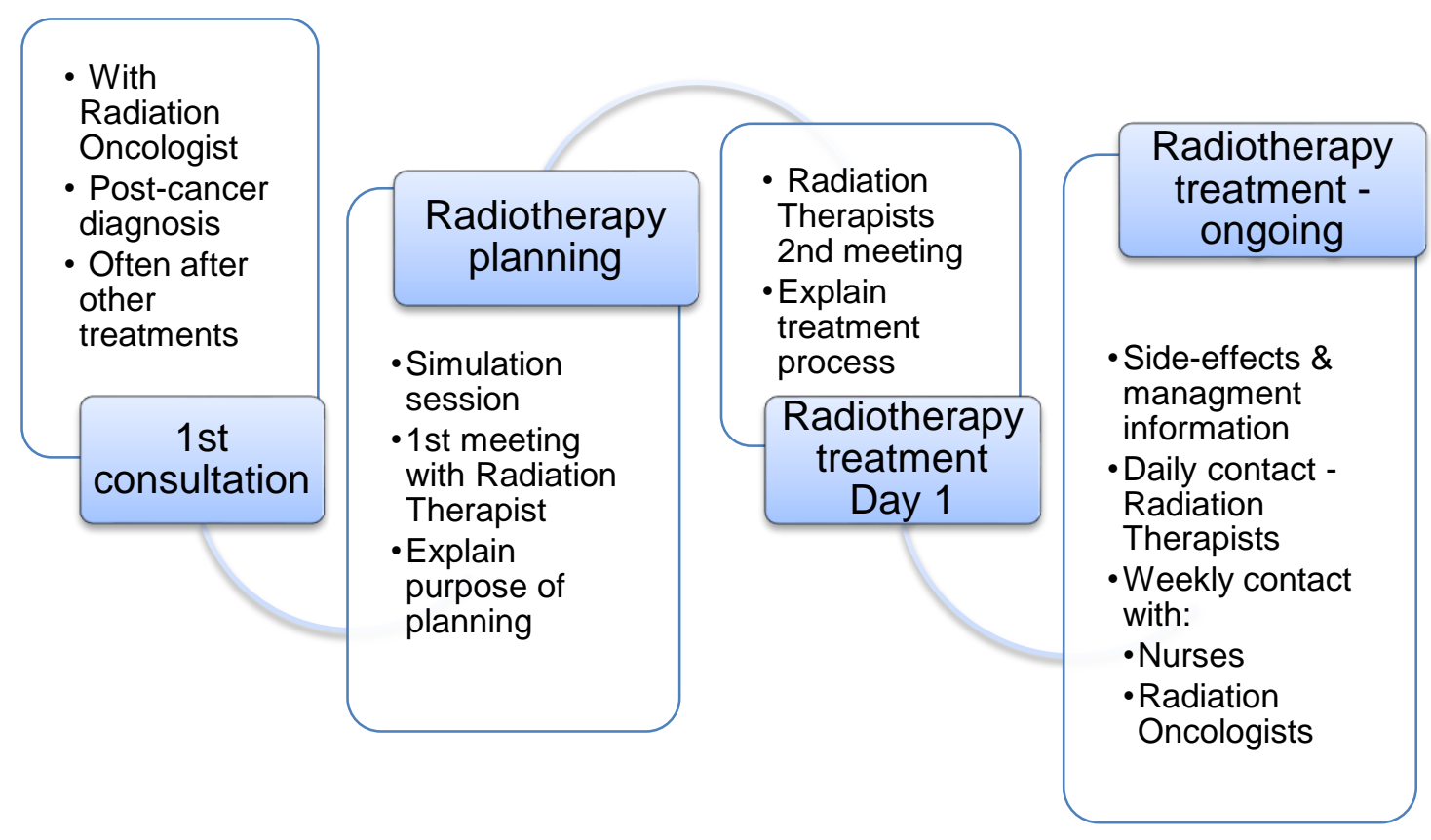

${ }^{*}$ Note: This is an example of what may happen at the different stages of the treatment trajectory, however information provision may vary at each time point between radiation oncology departments.

Ref: Halkett, G.K.B., et al., Meeting breast cancer patients' information needs during radiotherapy: what can we do to improve the information and support that is currently provided? European Journal of Cancer Care, 2010. 19(4): p. 538-47. 
Table 1 Health literacy levels [3]

\begin{tabular}{|l|l|}
\hline Type & Definition \\
\hline 1. Functional health literacy & $\begin{array}{l}\text { Basic reading comprehension and writing } \\
\text { skills to understand health } \\
\text { information/messages, together with } \\
\text { knowledge of health conditions, services } \\
\text { (e.g. treatment), and systems. }\end{array}$ \\
\hline 2. Communicative/Interactive health literacy & $\begin{array}{l}\text { Higher level communicative and social skills } \\
\text { required to extract and discuss health } \\
\text { information with others. }\end{array}$ \\
\hline 3. Critical health literacy & $\begin{array}{l}\text { Advanced literacy, cognitive, and social } \\
\text { skills to analyze information and make } \\
\text { informed health decisions. }\end{array}$ \\
\hline
\end{tabular}


Table 2 Demographic characteristics of the radiation therapists $(n=25)$

\begin{tabular}{|c|c|c|}
\hline Variables & Category & $\mathbf{N}$ \\
\hline \multicolumn{3}{|l|}{ Gender } \\
\hline & Male & 7 \\
\hline & Female & 18 \\
\hline \multicolumn{3}{|l|}{ Age (years) } \\
\hline & $20-29$ & 17 \\
\hline & $30-39$ & 4 \\
\hline & $40-49$ & 2 \\
\hline & $50-59$ & 2 \\
\hline \multicolumn{3}{|l|}{ Nationality } \\
\hline & Australian/Anglo & 20 \\
\hline & Asian-Middle Eastern & 5 \\
\hline \multicolumn{3}{|l|}{$\begin{array}{l}\text { Primary } \\
\text { language }\end{array}$} \\
\hline & English & 19 \\
\hline & Arabic & 1 \\
\hline & Chinese - Cantonese & 2 \\
\hline & Vietnamese & 2 \\
\hline & Tagalog & 1 \\
\hline \multicolumn{3}{|l|}{$\begin{array}{l}\text { Years of } \\
\text { experience }\end{array}$} \\
\hline & $\leq 5$ years & 14 \\
\hline & $6-10$ years & 4 \\
\hline & $11-20$ years & 3 \\
\hline & $>20$ years & 4 \\
\hline
\end{tabular}


Table 3 Verbal and non-verbal cues used by radiation therapists to identify people with low health literacy

\begin{tabular}{|c|c|}
\hline Type of cue & Range of cues described to identify health literacy difficulties during treatment \\
\hline \multicolumn{2}{|r|}{ 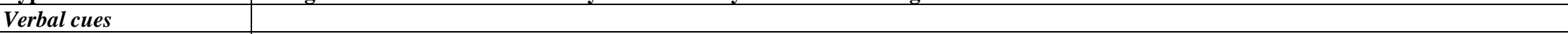 } \\
\hline General language ability & $\begin{array}{ll}\text { - } & \text { Limited vocabulary and/or use of medical terms. } \\
\text { - } & \text { Greater use of conversational/informal speech. } \\
\text { - } & \text { Poorly constructed sentences. } \\
\end{array}$ \\
\hline Question-asking & $\begin{array}{l}\text { - } \quad \text { Lack of question asking. } \\
\text { - } \quad \text { Hesitancy to ask questions. } \\
\text { - } \quad \text { Rifficulties articulating questions. } \\
\end{array}$ \\
\hline $\begin{array}{l}\text { Disclosure of } \\
\text { comprehension problems }\end{array}$ & $\begin{array}{l}\text { - Informing the therapist of their literacy/comprehension problems. } \\
\text { - } \\
\text { - } \\
\text { Asking for explanation of terms or medical jargon. } \\
\text { Asking therapist to verbally explain written information. }\end{array}$ \\
\hline $\begin{array}{l}\text { Verbal communication } \\
\text { skills - responses to } \\
\text { information provided }\end{array}$ & $\begin{array}{ll} & \text { Confirms understanding too readily: Repetition of 'yes' following information provision. } \\
\text { - } & \text { Difficulties answering questions posed by radiation therapist. } \\
\text { - } & \text { Brief responses or dismissing issue in order to move on. } \\
\text { - } & \text { Patient asks a family member or carer to communicate on their behalf. }\end{array}$ \\
\hline $\begin{array}{l}\text { Limited content } \\
\text { knowledge about cancer } \\
\text { and radiotherapy }\end{array}$ & $\begin{array}{ll} & \text { Displays limited understanding of key cancer concepts (e.g. diagnosis, treatment, prognosis). } \\
\text { - } & \text { Demonstrates limited knowledge of radiation therapy (it's purpose, possible side-effects, logistics). } \\
\text { - } & \text { Relies on outdated information. } \\
\text { - } & \text { Difficulties retaining information previously provided. }\end{array}$ \\
\hline \multicolumn{2}{|r|}{ о о } \\
\hline Non-verbal expressions & $\begin{array}{ll}\text { - } & \text { Avoiding eye contact. } \\
\text { - } & \text { Facial expressions: 'blank', 'puzzled', 'gazing off into space, 'confused', expressions remain fixed. }\end{array}$ \\
\hline $\begin{array}{l}\text { Ability to follow } \\
\text { recommended self-care } \\
\text { advice and instructions }\end{array}$ & $\begin{array}{l}\text { - } \quad \text { Experiences difficulties following advice for self-care/management of side effects. } \\
\text { - } \quad \text { Has trouble reading instructions (for self-care) or written information supplied. } \\
\text { - } \quad \text { Has difficulties following simple procedural instructions during the delivery of treatment. } \\
\text { - } \quad \text { Fails to turn up for appointments without notifying the cancer team. }\end{array}$ \\
\hline $\begin{array}{l}\text { Non-verbal } \\
\text { communicative skills - } \\
\text { responses to information } \\
\text { provided }\end{array}$ & $\begin{array}{l}\text { - } \quad \text { Confirms understanding too readily (e.g. by nodding). } \\
\text { - } \quad \text { Too readily signing off on written documents such as consent forms. } \\
\text { - } \quad \text { Person seems 'frustrated' or 'flustered' due to lack of understanding. } \\
\text { - } \quad \text { Unable to understand additional handwritten explanations supplied by therapist. }\end{array}$ \\
\hline $\begin{array}{l}\text { Notification of a person's } \\
\text { health literacy }\end{array}$ & - $\quad$ Radiation therapist is alerted by other team members (e.g. oncologist, nurse) about a person's health literacy difficulties. \\
\hline $\begin{array}{l}\text { Proxies for health literacy } \\
\text { difficulties }\end{array}$ & $\begin{array}{l}\text { - Socio-demographic characteristics - rural, remote, lower-socio-economic group, level of education, employment status, ethnicity, non- } \\
\text { Anglo, non-English speaking. }\end{array}$ \\
\hline
\end{tabular}


Table 4 Strategies described by radiation therapists to manage and respond to the needs of people with lower and higher health literacy Activity Strategies used by radiation therapists

Timing informatio Irrespective of health literacy

- Treatment planning and first day of treatment - key time points where RT provided a basic outline of what treatment entails.

- Staggering information provision as treatment progresses.

- Verify understanding and 'fill in' the missing knowledge, or refer to another member of the cancer team to explain.

- Reiterating information as information provided at the beginning may have been lost or forgotten as treatment progresses.

Tailoring communication to match health literacy level

$$
\text { Irrespective of health literacy }
$$

- At the beginning of treatment, information pitched at basic level.

- $\quad$ Communication and language tailored to health literacy level in accordance with verbal and non-verbal cues.

- Preference for verbal communication, but reinforced by visuals, written and audio-visual information.

- Use of visual prompts (e.g., model of radiotherapy mask, photos of CT machine or models of machinery in treatment room).

- $\quad$ Provision of information produced by the radiation oncology department (DVDs, written booklet/brochure).

- $\quad$ Risk communication - preference for qualitative descriptors (e.g. 'very unlikely') over numbers, more comfortable discussing

side effects than issues relating to the efficacy of treatment.

Patients perceived to have lower health literacy

- Greater use of plain/lay language.

- Minimal use of medical terminology.

- Convey the basic facts with minimal scientific or technical information

- Greater use of analogies to convey complex concepts (e.g. 'taking an x-ray is like taking a picture').

Patients perceived to have higher health literacy

- Provide information about the technical aspects of radiotherapy.

- Addressing 'why' rather than 'what' questions.

- Greater use of medical terminology/concepts, but avoided using highly specialized technical terms.

- Talking to them at 'their level' and not 'talking down'

- Reminders and prompts regarding scheduled appointments, medication and self-care.

- Check up on information processing throughout treatment and reinforcing the essential aspects.

- Inviting family members or support person with higher literacy to attend the consultation to help reinforce information to patient

- Going through written information with the patient and checking understanding. 